\title{
Saúde bucal na atenção primária à saúde: articulações entre o ensino e a estratégia de saúde da família
}

\author{
Oral health in primary health care: articulations between teaching and the \\ family health strategy
}

Patrícia Laguna ROSELINOa (i) Jaqueline Lopes DAMASCENOa (i) Glória Lúcia Alves FIGUEIREDO** (1)

aUNIFRAN - Universidade de Franca, Programa de Pós-graduação em Promoção da Saúde, Franca, SP, Brasil

\begin{abstract}
Como citar: Roselino PL, Damasceno JL, Figueiredo GLA. Saúde bucal na atenção primária à saúde: articulações entre o ensino e a estratégia de saúde da família. Rev Odontol UNESP. 2019; 48:e20190081. https://doi.org/10.1590/18072577.08119
\end{abstract}

\begin{abstract}
Resumo
Introdução: A saúde bucal na atenção primária à saúde, com profissionais da Odontologia aptos nesse campo de atuação, tem sido descrita como promissora estratégia para se promover saúde. Objetivo: Identificar e descrever as articulações intersetoriais e suas contribuições para a formação do profissional em Odontologia e para a saúde bucal de crianças de um município paulista. Material e método: Pesquisa de campo, do tipo transversal, de abordagem mista e de caráter intervencionista. Dados secundários foram obtidos dos prontuários e relatórios de estagiários em Odontologia. Foram realizados atendimentos odontológicos a 455 crianças da rede básica de ensino e oito entrevistas com os familiares das crianças faltosas aos atendimentos. Foi utilizada estatística descritiva, com frequência simples e porcentagem, e Análise de Conteúdo para os dados qualitativos. Resultado: Verificou-se que $42 \%$ das crianças encontravam-se em situação de alto risco à doença cárie. Os traumas e medos, e o escasso conhecimento de higiene bucal das crianças e dos pais influenciaram negativamente no cuidado com a saúde bucal. No consultório odontológico, as fragilidades apontadas pelos familiares foram o despreparo profissional, que vão desde questões técnicas até formas de abordagem pessoal. Conclusão: Conclui-se que a prática na atenção primária à saúde aproximou os universitários da realidade social e ampliou e diversificou os cenários de ensino-aprendizagem com maior tempo para educação em saúde. Contudo, há necessidade de mais pesquisas sobre as experiências curriculares efetivas nessa temática.
\end{abstract}

Descritores: Atenção primária à saúde; colaboração intersetorial; estratégia saúde da família; educação em saúde; acesso aos serviços de saúde.

\begin{abstract}
Introduction: Oral health in primary health care, with qualified dental professionals in this field, has been described as a promising strategy to promote health. Objective: To identify and describe intersectoral articulations, and their contributions to dental professional education, and oral health of children from a city of São Paulo - Brazil. Material and method: Field research, cross-sectional, mixed approach and interventionist character. Secondary data were obtained from medical records and reports of dental interns. Dental visits were performed to 455 children from the basic education system and eight interviews with the family members of the children who missed the visits. Descriptive statistics, with simple frequency and percentage, and Content Analysis were used for qualitative data. Result: It was found that $42 \%$ of the children were at high risk for caries disease. Traumas, fears and poor knowledge of oral hygiene of children and parents had a negative influence on oral health care. In the dental office the weaknesses pointed out by family members were professional unpreparedness, ranging from technical issues to forms of personal approach. Conclusion: It is concluded that the practice in primary health care brought the students closer to social reality, expanded and diversified the teaching-learning scenarios with longer time for health education. However, there is a need for further research on effective curriculum experiences in this area.
\end{abstract}

Descriptors: Primary health care; inter-sectoral collaboration; family health strategy; health education; access to health services. 


\section{INTRODUÇÃO}

A saúde bucal integra a saúde e bem-estar geral do indivíduo, sendo considerada importante para uma boa qualidade de vida. Em vários países, observa-se um forte declínio na média geral de dentes acometidos pela cárie, além de um aumento na quantidade de pessoas que nunca passaram por essa experiência. No início da década de 1970, nos países industrializados mais desenvolvidos, o índice de cárie médio em crianças de 12 anos de idade variava entre cinco e nove dentes acometidos pela doença em cada indivíduo. Após vinte anos, o índice foi reduzido para cerca de um dente ${ }^{1}$.

Na análise dessa realidade pela ótica da Atenção Primária a Saúde (APS), no Brasil, remete-se à problemática geral dos serviços de assistência à saúde, em destaque a odontológica. Além do aspecto econômico desfavorável, o acesso da população à saúde bucal mostra-se extremamente difícil, limitado e pautado no modelo assistencial curativo².

No cenário mundial, o Cirurgião-Dentista (CD) atua predominantemente no setor privado. No Brasil, a sua inserção no serviço público foi recomendada em 2002 pelas Diretrizes Curriculares Nacionais (DCN), para os cursos de graduação na área de saúde, e reforçada com a reorganização da APS, por meio da Estratégia Saúde da Família (ESF). Associada à Política Nacional de Saúde Bucal (PNSB) e à Política Nacional de Atenção Básica (PNAB), essa inserção no serviço público contribuiu para o deslocamento da formação do CD para o campo da Saúde Bucal Coletiva ${ }^{3}$.

Mecanismos diversos têm sido propostos nos projetos pedagógicos dos cursos de graduação para possibilitar o desenvolvimento da sensibilidade social entre os acadêmicos. Entre estes, o envolvimento do estudante de Odontologia em projetos comunitários, atividades práticas e trabalhos extramuros em conjunto com estudos dos processos saúde-doença e junto à comunidade ${ }^{4}$.

Na tentativa de melhorar a formação dos recursos humanos em saúde, segundo as DCNs ${ }^{5}$ para o Curso de Odontologia, uma Instituição Privada de Ensino Superior (IES), no interior do estado de São Paulo, pactuou com gestores de uma cidade próxima, que conta com 100\% de cobertura da ESF, a possibilidade de oferecer tratamento odontológico à população infantil, como campo de estágio para os graduandos de Odontologia supervisionados por docentes profissionais dentistas.

Assim, os estudantes, desde 2014, cumprem estágio Extramuros em Saúde Coletiva e realizam atividades educativas de promoção da saúde e tratamento restaurador atraumático (TRA) com os escolares de seis a 12 anos desse município paulista. Frente a casos mais complexos, os pais da criança são comunicados, orientados e recebem o encaminhamento com dia e horário da consulta agendada com o Cirurgião-Dentista da ESF.

Ao se incorporar a realidade social das comunidades ao ensino em Odontologia, a formação profissional amplia-se na perspectiva da APS, como um todo, e para a ESF, em particular. Porém, a integração e articulação entre os setores da educação e saúde, ainda pode ser considerada tímida, limitando-se muitas vezes a ações isoladas, o que justifica a elaboração do presente artigo, que apresenta como objetivo identificar e descrever as articulações intersetoriais e suas contribuições para a formação do profissional em Odontologia e para a saúde bucal de crianças de um município paulista.

\section{MATERIAL E MÉTODO}

Trata-se de estudo exploratório, do tipo transversal, de abordagem mista, cuja amostra se constituiu por estudantes do curso de graduação em Odontologia da Universidade de Franca. Foi aprovado pelo Comitê de Ética em Pesquisa da Universidade de Franca 
(CAAE n. 37034314.9.0000.5495), conforme diretrizes para a realização de pesquisa envolvendo seres humanos.

Foi realizado em um município de aproximadamente 6.587 habitantes, localizado no interior do estado de São Paulo, com índice de Desenvolvimento Humano (IDH) de 0,705. No período de estudo, a atenção à saúde contava com uma Unidade Básica de Saúde (UBS) e duas equipes de saúde da família (EqSF), oferecendo uma cobertura de 100\% às 1.416 famílias cadastradas. As EqSFs possuem equipe de saúde bucal (modalidade I) que atendem a demanda espontânea, urgências e emergências. 0 atendimento odontológico realizado na UBS do município é executado por três Cirurgiões-Dentistas, atendendo diariamente uma média de 30 pessoas em demanda espontânea, sem limite de faixa etária. Na atenção terciária à saúde, o município de referência está a $10 \mathrm{~km}$ de distância.

No setor da educação pública, o município possui uma escola de Educação Infantil, duas escolas de Ensino Fundamental (uma de primeira a quinta série e outra de sexta a nona série) e uma de Ensino Médio. A escola de Ensino Fundamental de primeira a quinta série foi o local de pesquisa.

O número de crianças na faixa etária entre seis a 12 anos, matriculadas e convidadas a participar da pesquisa foi de 521. A amostra foi composta por 455 crianças participantes, que entregaram a autorização assinada pelos responsáveis para avaliação e atendimento odontológico a serem realizados no ambiente escolar pelos graduandos de Odontologia.

Para organização e garantia do acesso ao tratamento das crianças com problemas dentários, optou-se pela ferramenta para classificação de risco individual proposta pela Secretaria de Estado da Saúde de São Paulo (SES/SP) para cárie, apresentada no Quadro 1, a ser realizada pelos estagiários, com as crianças individualmente, no período letivo e no espaço escolar. Nessa metodologia, os critérios de risco em relação à cárie dentária classificam os indivíduos em seis grupos, codificados nas letras de A a F, segundo Quadro 1.

Quadro 1. Critérios para classificação de risco à doença cárie

\begin{tabular}{|c|c|c|}
\hline CLASSIFICAÇÃO & GRUPO & SITUAÇÃO INDIVIDUAL \\
\hline Baixo Risco & A & $\begin{array}{l}\text { Ausência de lesão de cárie, sem placa visível, sem gengivite e/ou sem } \\
\text { mancha branca ativa }\end{array}$ \\
\hline \multirow{2}{*}{ Risco Moderado } & B & $\begin{array}{l}\text { História de dente restaurado, sem placa, sem gengivite e/ou sem } \\
\text { mancha branca ativa }\end{array}$ \\
\hline & $\mathrm{C}$ & $\begin{array}{l}\text { Uma ou mais cavidades em situação de cárie crônica, mas sem placa, } \\
\text { sem gengivite e/ou sem mancha branca ativa }\end{array}$ \\
\hline \multirow{3}{*}{ Alto Risco } & $\mathrm{D}$ & $\begin{array}{l}\text { Ausência de lesão de cárie aguda e/ou dente restaurado, mas com } \\
\text { placa, gengivite e/ou mancha branca ativa }\end{array}$ \\
\hline & E & Uma ou mais cavidades em situação de lesão de cárie aguda \\
\hline & $\mathrm{F}$ & Presença de dor e/ou abcesso \\
\hline
\end{tabular}

Fonte: Secretaria Municipal da Saúde ${ }^{6}$.

As crianças classificadas no grupo $\mathrm{F}$ teriam a garantia do acesso ao tratamento odontológico imediato. Os classificados em B, D e A seriam incluídos em ações coletivas de educação e prevenção; entretanto, se apresentassem alguma necessidade de intervenção individual, tais como fraturas dentárias ou restaurações inadequadas, também seriam incluídos na assistência odontológica. As crianças classificadas como C e E passariam pelo Tratamento Restaurador Atraumático (TRA), a ser realizado no ambiente escolar, em espaços disponíveis e/ou salas de aula.

O TRA foi desenvolvido em meados dos anos 1980, na Tanzânia, como parte de um programa de atenção à saúde bucal. Essa técnica indolor destaca-se pela simplicidade, não requerendo anestesia e utilização de equipamentos sofisticados, e dispensando o uso de energia elétrica. Além 
disso, possui uma relação custo/benefício satisfatória e promove um efetivo controle à cárie. Sua abordagem principal é a de máxima prevenção e mínima intervenção, obtendo um resultado final equivalente às restaurações realizadas com procedimentos restauradores convencionais ${ }^{7-9}$.

Após o atendimento na escola, aquelas crianças que necessitassem de tratamento odontológico, seriam agendadas e encaminhadas para os dentistas da ESF. Destas, as que não comparecessem à ESF para o tratamento odontológico, o pesquisador realizou uma entrevista semiestruturada com as famílias. Para esses dados qualitativos, utilizou-se a Análise de Conteúdo

Para caracterização das famílias, foram utilizados os dados cadastrais da ESF, tais como: número de pessoas no domicílio, escolaridade dos responsáveis, renda familiar e ocupação dos responsáveis. Para os dados qualitativos, realizaram-se entrevistas não estruturadas, iniciando-se com a pergunta: "Como tem sido o cuidado com a saúde bucal do seu(sua) filho(a)?", seguida de "Quando procuram atendimento de saúde?", "Quando procuram o Cirurgião-Dentista?". As entrevistas foram gravadas e transcritas, respeitando a linguagem utilizada. E, para garantir o anonimato, as entrevistas foram identificadas pela letra $\mathrm{F}$ (família) seguida de número, pois os entrevistados (pais ou responsáveis) representaram as famílias das crianças faltosas. Dessa forma, foi utilizado F1 para a família de número 1 e assim sucessivamente.

Justifica-se a utilização de abordagem qualitativa, ao se tentar compreender a influência que os acontecimentos e interações de situações vivenciadas tem para os indivíduos estudados. Ao utilizar-se a Análise de Conteúdo proposta por Bardin ${ }^{10}$, procurou-se descrever de forma objetiva e sistemática o conteúdo manifesto da comunicação. A categorização principal, foi definida a priori, com objetivo de compreender o não comparecimento das crianças ao atendimento.

Os dados secundários foram obtidos do Departamento de Informática do SUS (DATASUS) e do Projeto Pedagógico de Curso e Relatórios de estágio dos graduandos em Odontologia. Para análise dos dados quantitativos, foi utilizada estatística descritiva, com frequência simples e porcentagem.

\section{RESULTADO}

É fato que, mesmo diante das tentativas de reorganização da atenção à saúde bucal, inúmeras têm sido as dificuldades apresentadas para a mudança do modelo assistencial e para o fortalecimento e a disseminação da rede básica. Contribuem para esse quadro a instabilidade econômica no país e a consequente insuficiência de investimentos financeiros e humanos, passando pela incipiente gestão dos serviços e pela distância geográfica entre as unidades de saúde. Para tanto, fazem-se necessários profissionais capacitados e preparados para esse novo momento.

Segundo as $\mathrm{DCNs}^{5}$, o cumprimento da carga horária de estágio curricular não deve ultrapassar $20 \%$ da carga horária total do curso, ficando a critério da IES a carga horária para as atividades intra e extramuros. Na IES estudada, a carga horária do estágio é de 800 horas, sendo 160 horas específicas do estágio extramuros nos dois últimos semestres. É importante apontar que esses alunos são supervisionados por docentes dentistas com formação em saúde coletiva e experiência em serviço público e gestão do SUS.

Para o processo de planejamento do estágio extramuros, houve em 2013 um movimento de aproximação entre as coordenações da área da educação (IES e Educação Básica) e da saúde (Secretaria de Saúde), para o desenvolvimento do estágio do Curso de Odontologia, que segue sendo negociado anualmente. Há de se ressaltar o caráter dialético e desafiador desse processo para o atendimento à diversidade de demanda no modelo de atenção em saúde bucal adotado pelo município. 
Entre as responsabilidades do município, pode-se citar o transporte dos estagiários da IES até o campo de estágio, além do provimento dos materiais de consumo a serem usados durante a execução das atividades clínicas. Ao estagiário e aos supervisores, ficou a incumbência de classificar a situação individual de cada aluno para o risco à doença cárie e efetuar o devido encaminhamento ao dentista da ESF.

Os resultados desta primeira etapa estão demonstrados na Tabela 1. Verificou-se que $42 \%$ estavam em situação de alto risco à doença cárie e nota-se que 34\% da amostra passou pelo Tratamento Restaurador Atraumático (TRA). Os estagiários realizaram 617 restaurações atraumáticas com cimento de ionômero de vidro e 454 selantes ionoméricos nos indivíduos classificados como C e E.

Tabela 1. Distribuição percentual dos participantes segundo classificação de risco à doença cárie. Franca/SP, 2015

\begin{tabular}{cccc}
\hline CLASSIFICAÇÃO & GRUPO & n & \% \\
\hline Baixo risco & A & 141 & 31 \\
Risco moderado & B & 45 & 10 \\
& C & 77 & 17 \\
Alto risco & D & 100 & 22 \\
& E & 77 & 17 \\
TOTAL & F & 15 & 3 \\
\hline
\end{tabular}

Fonte: Dados da pesquisa; n: Número de indivíduos.

É fato que os benefícios do TRA apenas se consolidam quando associados à adoção de medidas de controle do biofilme7,9. Portanto, os estagiários, acompanhados do docente, ficaram incumbidos da educação bucal. Realizaram a escovação supervisionada nas crianças na escola, na tentativa de sensibilizá-los quanto ao autocuidado com a higiene oral, mas desde que apresentassem autorização dos pais por escrito. Em seguida, as crianças receberam um kit, contendo escova dentária, dentifrício e fio dental, fornecido pela Secretaria Municipal de Saúde.

Esse critério de classificação de risco do MS tem sido utilizado pelo governo do Estado de São Paulo na tentativa de organização da demanda de atendimento. Kobayashi et al. ${ }^{11}$ realizaram uma pesquisa utilizando essa estratégia com indivíduos de 12 anos de idade, obtendo os seguintes resultados: 21,3\% com Baixo Risco (A); 1,3\% Risco Moderado (B); 21,3\% Risco Moderado (C), 2,7\% Alto Risco (D), 33,4\% Alto Risco (E) e 20\% com Alto Risco (F).

Comparando aos resultados encontrados neste estudo, as crianças do município estudado apresentaram uma realidade de saúde bucal melhor que o estudo citado. Contudo, para 23 crianças (5\%), especificamente, devido ao estágio avançado de evolução da cárie, houve necessidade de extrações dentárias e também de tratamento endodôntico. Elas foram encaminhadas para atendimento em consultório odontológico na ESF. Os responsáveis por essas crianças foram comunicados por escrito, contatados pela ACS em visita domiciliar e/ou pela Auxiliar em Saúde Bucal (ASB) por telefone para que levassem os filhos em data agendada para a consulta odontológica na ESF.

No entanto, após várias tentativas, dez crianças não compareceram às consultas marcadas e foram, portanto, incluídas na segunda etapa deste estudo. Seus responsáveis receberam uma visita domiciliar do pesquisador, em que foram explicados os objetivos do estudo. Mesmo ante as explicações, dois não concordaram, alegando falta de tempo e indisponibilidade, resultando em uma segunda amostra composta por oito famílias participantes.

A responsabilidade pelos cuidados e pelo acesso das crianças aos serviços de saúde infantil, especialmente a saúde bucal, tem sido atribuída às famílias ou aos seus cuidadores. Com isso, a 
dependência das crianças ao acesso e acompanhamento para a manutenção da saúde bucal vem dificultando o ajuste da oferta e demanda desse serviço. Dessa forma, levanta-se a necessidade de estudos sobre as características desse acesso, principalmente da não procura ou comparecimento ao atendimento odontológico.

Estudos evidenciaram associação entre saúde bucal precária das crianças e as características sociodemográficas das famílias. Vários fatores influenciaram: dificuldades de acesso; desconhecimento e medo dos pais sobre cuidados em saúde bucal; baixa renda familiar; idade e escolaridade da mãe; quantidade de pessoas residentes no mesmo domicilio; parentes com histórico de cárie anterior; hábitos de higiene precários da família, e consumo de açúcar antes dos 18 meses de vida ${ }^{12,13}$.

Foram realizadas no mínimo duas entrevistas com as famílias das crianças faltosas ao atendimento odontológico, sendo que cada entrevista teve a duração média de 15 minutos. Em sete domicílios, o pesquisador foi recebido pelas mães das crianças e, somente em uma, pelo pai. A partir dos dados coletados pelo cadastro da ESF, verificou-se o perfil sociodemográfico das famílias desta pesquisa (Tabela 2).

Tabela 2. Perfil sociodemográfico das famílias estudadas. Franca/SP, 2015

\begin{tabular}{|c|c|c|c|c|c|c|}
\hline & \multirow{2}{*}{$\begin{array}{c}\text { Número } \\
\text { de pessoas } \\
\text { no } \\
\text { domicílio } \\
\end{array}$} & \multicolumn{2}{|c|}{$\begin{array}{l}\text { Escolaridade dos } \\
\text { responsáveis (em } \\
\text { anos estudados) }\end{array}$} & \multirow{2}{*}{$\begin{array}{c}\text { Renda } \\
\text { familiar } \\
\text { (em reais) }\end{array}$} & \multicolumn{2}{|c|}{ Ocupação dos responsáveis } \\
\hline & & Pai & Mãe & & Pai & Mãe \\
\hline Família 1 & 5 & 11 & 8 & 1800 & operador de máquinas & do lar \\
\hline Família 2 & 7 & 8 & 4 & 2000 & vigia & do lar \\
\hline Família 3 & 4 & 11 & 13 & 2000 & comerciante & professora \\
\hline Família 4 & 7 & 2 & 3 & 500 & auxiliar de limpeza & do lar \\
\hline Família 5 & 3 & 11 & 9 & 1200 & comerciante & do lar \\
\hline Família 6 & 3 & 11 & 13 & 2000 & comerciante & estudante \\
\hline Família 7 & 5 & - & 4 & 1000 & - & auxiliar de cozinha \\
\hline Família 8 & 8 & 1 & 1 & 600 & trabalhador rural & do lar \\
\hline
\end{tabular}

Fonte: Dados da pesquisa.

Entre as famílias, o número de pessoas nos domicílios variou de três a oito pessoas. Quanto à escolaridade, os dados foram bem divergentes, de dois a 13 anos de estudo, com predominância dos pais com maior escolaridade. A maior renda familiar ficou abaixo de $\$ 700,00$ per capita e todos os pais estavam no mercado de trabalho.

\section{DISCUSSÃO}

Após a transcrição das entrevistas, as duas categorias de análise derivadas da categorização principal, de compreender o não comparecimento ao atendimento das crianças ao atendimento, foram: Acesso aos serviços de saúde; Experiências familiares com a saúde bucal.

Acesso aos serviços de saúde

O modo como são produzidas as ações de saúde e a maneira como os serviços as distribuem são resultantes de interesses institucionais e de confrontos individuais, que refletem as políticas públicas adotadas. O SUS orienta-se pelo princípio de acesso universal e igualitário. E o acesso aos serviços públicos de saúde expressa características dessa oferta, que podem facilitar ou obstruir a possibilidade de usarem os serviços de saúde quando necessitam ${ }^{14}$.

0 acesso ao serviço em saúde tem sido discutido na literatura, inclusive com a formulação de categorias que possam facilitar o entendimento do acesso ou não acesso. Na tentativa de classificar os fatores que possam interferir no acesso, alguns autores dividem as categorias em: 
(a) geográfico, caracterizado pelo tempo de deslocamento e pela distância entre a residência do usuário e o serviço de saúde; (b) econômico, caracterizado a partir de facilidades e dificuldades que o usuário encontra para obter o atendimento, como forma e custos de deslocamento e de procedimentos, obtenção de medicamentos e condição social atual; (c) dimensão técnica, que envolve desde a entrada propriamente dita aos serviços de que o cidadão necessita, incluindo-se os horários previstos de atendimento e a qualidade da atenção, visando ao acolhimento ${ }^{15,16}$.

0 processo de utilização dos serviços de saúde resulta da interação do comportamento do indivíduo que procura cuidados com o comportamento do profissional que o conduz dentro do sistema de saúde ${ }^{17}$. Observa-se que o acesso ao atendimento médico se mostrou disponível para algumas das famílias entrevistadas:

Eu sempre to lá no postinho [...] é tanto remédio, tanto médico [...] os remédio dele pego tudo lá de graça [...] (F1).

Nota-se que o acesso aos serviços de saúde é fortemente influenciado pela condição social das pessoas e pela localização que residem. Além da indisponibilidade para o atendimento, outras dificuldades cercam a efetivação das práticas de saúde. Certas características dos serviços poderão originar barreiras de acesso, como, por exemplo, o modo como são abordados, a qualidade dos profissionais, o cuidado recebido e as informações sobre o sistema de saúde.

Durante as entrevistas, pode-se observar algumas dessas barreiras de acesso:

$O$ atendimento do postinho é bom, só que tem que esperar muito lá pra chamar [...] o médico demora, acho que só tem um sabe...ai demora mesmo. Aí você vai, perde a manhã toda e atrapalha o almoço do homem, e ele encrenca comigo [...] (F2).

É difícil pra gente ir lá toda hora que precisa, não é perto, e tem os otros fio, que ficam aqui com eu. Fico o dia todo por conta desses menino [...] (F4).

Assis, Jesus ${ }^{15}$, em uma pesquisa sobre acesso, descreveram que a demora para conseguirem um atendimento e, em alguns casos, a dificuldade de comparecerem várias vezes na unidade de saúde para consegui-lo interferiram na busca ao serviço. A distância entre o domicílio e o atendimento, descrita como barreira para o acesso, também foi identificada.

Mediante a dificuldade e/ou demora para conseguir o atendimento médico no serviço público, as famílias encontram soluções. Os entrevistados relataram procurar o atendimento só quando realmente necessário, mas, se fosse possível, pagariam um atendimento particular.

A gente sempre teve convênio médico e tratava tudo [...] Médico, dentista, tudo. Aí depois [...] tivemos que parar e comecei a usar o serviço (de saúde) daqui mesmo [...], mas até que é bom, apesar de meio demorado (F3).

O estabelecimento de vínculos e a criação de laços de compromisso e de corresponsabilidade entre os profissionais de saúde e a população é uma das diretrizes estabelecidas para a ESF. 0 vínculo estabelecido entre as famílias e as EqSFs garante laços de confiança para a integralidade da assistência e o acolhimento das necessidades de saúde da população proporciona melhoria nas condições de vida das pessoas ${ }^{15}$. Como pode-se observar nas falas a seguir:

As meninas do ESF, ajuda bem viu...passa aqui, vê se a gente tá bem, a gente pega leite lá dia de terça e quinta, lembra das vacina, marca médico [...] (F4)

A agente passa aqui sempre, fala das vacinas, quando tamo doente ela arranja médico, [...] fala de higiene, limpeza, e como prevenir umas coisas também. Eu gosto dessa atenção (F8). 
Sabe-se que as condições socioeconômicas e a escolaridade dos responsáveis pelas famílias são fatores que influenciam diretamente na utilização dos serviços. No caso das crianças, o acesso aos serviços de saúde agrava-se uma vez que elas dependem da disponibilidade e do reconhecimento dessa necessidade por parte de seus responsáveis.

Durante as entrevistas, pode-se constatar a dificuldade das famílias em resolver os problemas de saúde bucal presentes:

[...] agora dentista é mais difícil né, não tem vaga e não fazem tudo o que a gente precisa, tipo canal, prótese [...] aí vai lá, eles querem arrancar e não colocam nada no lugar. Do meu filho eu sei que vai nascer outro, mas o meu sei que não, então a gente acaba deixando passar né? E fica com os dentes tudo danado (F3).

A realidade da atenção em saúde bucal nem sempre pode ser considerada a que foi proposta pelos paradigmas instituídos. Ao profissional, foi atribuída a responsabilidade de assegurar o tratamento integral, buscando alcançar a população adscrita da ESF, porém não foi considerada a grande demanda reprimida. Isto dificulta a execução do trabalho, em que predomina a demanda espontânea, pois os profissionais não conseguem finalizar os tratamentos necessários, tampouco trabalhar a proposta da PNSB ${ }^{18}$.

A demanda presente nos serviços de saúde normalmente reverte em práticas que visam atender às necessidades e à resolução de problemas de saúde com maior prevalência da comunidade daquele território. Entretanto, as pessoas que não procuram o serviço restringem a compreensão de suas demandas por desconhecimento dos profissionais que ali atuam.

Quando eu fui lá, deve te uns 3 meses, por que um dente meu quebrou, eles só puseram uma massinha e falaram que tinha fila pra fazer direito [...] to esperando. Mas a dentista nem olhou direito pra mim sabe [...] tava cheio de gente, ela só limpou e colocou essa massinha aqui [...], até que ta durando sabe. Não é fácil dentista aqui não moça [...] Médico é mais fácil, sempre tem, mas dentista [...] eles só atendem a gente quando a gente vai lá porque quebrou, porque tá doendo e não consegue continuar o tratamento sabe, fazer tudo que tem pra fazer? Fica só com essas massinhas, esperando te chamarem da tal fila (F1).

Novamente, mediante a dificuldade e/ou demora para conseguir o atendimento médico no serviço público, as famílias fazem suas escolhas. Nas entrevistas realizadas, foi constatado que o atendimento odontológico se limitou normalmente à resolução imediata de problemas, como dor ou fraturas.

[...] os meninos eu levava quando aparecia algum buraco no dente, ou eles falavam de dor, mas agora eles tão maior, então eles vão [...] mas só vai pra arrancar $[. .].(\mathrm{F} 2)$

Considerar o respeito à garantia do acesso ao serviço de saúde vai além do estabelecido pelo MS, pois a organização da APS requer a articulação entre o que foi normatizado, o contexto municipal, o preparo e a disponibilidade da equipe para implementação da proposta de reorganização do modelo assistencial13,19.

A formação do profissional, quando baseada no tecnicismo e no modelo biomédico, pode comprometer a estratégia, reduzindo o acesso ao serviço. A inadequação no preparo dos recursos humanos, precocemente direcionados para as especialidades e totalmente dissociados das características dos serviços públicos, os tornam desvinculados das reais necessidades do país ${ }^{20}$.

Atender toda a demanda em saúde bucal nos serviços públicos de saúde é uma dificuldade presente no cotidiano de trabalho das equipes. Porém, outras barreiras também puderam ser verificadas nos relatos das famílias:

Tem o dentista lá do posto, já fui lá uma vez [...] quando fui arrancar um dente do fundo. Não gostei dele não, falou que eu não cuidava dos meus dentes e que ia perder tudo, e tava lá reclamando que não gostava de atender menino. Pra que vou sair de casa para levar lá? Eu não (F8) 
A inadequação dos recursos humanos em Odontologia revela-se no despreparo dos profissionais em ver o paciente como um ser integral e buscar compreender o seu papel como profissional de saúde, não apenas como executor técnico de procedimentos, mas, também, como cidadão, tal qual preconizado pelo SUS. Essa é uma das competências a serem adquiridas no processo formativo do profissional.

A formação do profissional de saúde deveria enfatizar o desenvolvimento do espírito crítico, da capacidade humanizadora, para promover acolhimento e busca de soluções aos problemas na realidade da APS. Mas, contraditório a essas barreiras e dificuldades de acesso, os pais, quando questionados sobre o atendimento odontológico de seus filhos, justificaram:

[...] ele não foi ainda não [...] ta doendo o dele também [...] mas não lembrei de marca não. Tinha até marcado a um tempo atrás, mas me esqueci de levar, ele reclama de dor às vezes, mas depois pára, ai esqueci [...] (F4).

O mais novo é o que mais sofre, fez até um tratamento na escola que ele estuda, mas marcaram para ir no postinho, porque ele tinha que arrancar uns dentes e fechar outros, mas nem sei porque não levei [...] coitado do meu menino, está meio largado [...] (F3).

Apesar do esquecimento, os pais não buscaram remarcar o atendimento acreditando na perda da vaga ou na impossibilidade de remarcação, devido à dificuldade de acesso, como se pode observar na fala do responsável:

Perdi a vaga dele? Ou se ligar dá para levar ainda? (F3).

Após as entrevistas, a maioria dos entrevistados mostrou interesse em remarcar o atendimento de seus filhos e realizaram perguntas ao pesquisador sobre saúde bucal, mostrando vontade em obter esclarecimentos sobre o atendimento em saúde bucal no município e os seus direitos como usuários do SUS. Nota-se a necessidade de capacitação especializada aos ACS para poderem agir como agentes em saúde bucal, assim como oportunidades de encontro com os profissionais da EqSF sem que seja por motivos de doença.

Os programas educativos em saúde bucal com as crianças, em geral, são realizados no ambiente escolar. Porém, nem sempre pode-se medir a eficácia, a frequência de execução e os resultados dessas atividades, pois muitas vezes foram executadas de forma pontual ${ }^{21}$.

Ao entrar na fase adulta, os pais ou responsáveis possuem hábitos de saúde intrínsecos e nem sempre corretos em sua execução. Ao se investigar a saúde bucal das crianças, no caso os filhos desses adultos, deve-se questionar a capacidade de explanação e inserção desses cuidados de forma adequada na rotina dos filhos. Evidencia-se a necessidade de revisão dos programas educativos que normalmente ocorrem somente em idade escolar e nem sempre atingem os adultos, que são os responsáveis diretos pelo cuidado ${ }^{15,18}$.

Pode-se constatar a importância da educação em saúde bucal no relato a seguir:

[...] Acho que vocês tinha que fazer isso com a gente, os pais, também lá na escola [...] porque a maioria nem sabe que tem que levar os menino no dentista [...] eu não sabia [...] a gente achava que só depois de cair os dente é que tinha que levar sabe [...] mas agora minha menina ensinou que até de nenê tem que cuidar. (risos).. imagina só, ela ensinar a gente [...] mas nem o dentista que a gente vai falo nada disso. Só vai lá, olha, faz o que tem que fazer, mas não fala nada para ensinar não [...] na escola tão de parabéns [...] os filhos tão ensinando os pais como cuidar dos dentes [...] (risos) (F6).

Algumas pessoas podem apresentar medo ou ansiedade em proporções maiores que a esperada durante um tratamento odontológico, podendo acarretar prejuízos em sua saúde bucal. A tendência sinaliza que esses indivíduos evitaram o profissional de saúde bucal, com frequência 
inconstante às consultas odontológicas. Esse comportamento é verificado na falta à consulta agendada ou na desistência ao tratamento ${ }^{22}$.

0 medo do tratamento dental tem sido correlacionado a hábitos de higiene bucal deficiente em adultos. Consequentemente, os filhos de pais que possuem trauma ou medo do cirurgião dentista poderão repetir o mesmo comportamento, adquirindo maus hábitos relacionados aos cuidados em saúde bucal ${ }^{23}$.

Os pais transmitem aos filhos seus conhecimentos, suas experiências, influenciando segundo suas condições psíquicas e comportamentais ${ }^{24}$. Como pode ser verificado nos relatos, a seguir:

Os dentistas daqui até que são bons, melhor que o da Paraíba [...] mas tenho medo do mesmo jeito [...] acho que passo isso pros fio, porque eles tudo tem medo também! (F5).

Eles não têm medo não, eu que tenho, mais nem vai ser em mim né? Preciso mudar isso sabe [...], mas aqui é meio longe de lá, com essas crianças pequena fica difícil. Tenho que pedir pra vizinha ficar com o nenê e a menor [...] ai fica devendo favor [...] mas se eles continua com dor vou ter que ir, não vai ter jeito não [...] (F4).

Na verdade, até hoje da minha menina não procurei ainda não [...] só meu marido foi esses dias porque tava com dor. Eu tenho medo, não vou, não gosto. Ano passado tive dor e fui, mas não gosto (F6).

O medo do profissional dentista, quando comparado ao medo de outros profissionais da saúde, tem se mostrado frequente e intensamente vivenciado, talvez pela crença ou por experiência anterior de algum desconforto durante o tratamento. Além disso, a atuação tecnicista do dentista, produto de um sistema de ensino em que habilidades manuais e procedimentos tecnológicos são priorizados, em detrimento de uma atuação mais humanística, exigida pela proximidade física e pelo estado emocional vulnerável de muitos pacientes ${ }^{22}$.

O trauma dos pais em relação ao atendimento odontológico demonstrou ter influenciado no não comparecimento de seus filhos ao agendamento. Talvez, na tentativa de poupar possível sofrimento dos filhos, os pais minimizam a necessidade em saúde bucal para evitar o sofrimento vivenciado por eles em experiências anteriores com o atendimento odontológico.

\section{CONCLUSÃO}

Apesar das tentativas de mudança do modelo assistencial no campo da saúde bucal, muitos são os fatores que interferem no acesso aos serviços públicos de saúde, sejam estes sociais, estruturais, organizacionais ou pessoais.

O desenvolvimento do estágio em saúde coletiva aproximou os universitários da realidade social, ampliando e diversificando os cenários de ensino-aprendizagem com orientação docente. Ampliou-se o campo de atuação e a formação de recursos humanos em Odontologia na APS. Destarte, espera-se que a formação ampliada na perspectiva da APS resulte em profissionais interessados em melhorar a atenção à saúde pública no país e a qualidade de vida da população.

Verificou-se que as famílias pesquisadas não vêm encontrando solução para seus problemas nesse atendimento. Segundo os relatos, as famílias não estavam convencidas ou conscientes da importância da saúde bucal. As experiências negativas no consultório odontológico apontaram despreparo profissional, que vai desde questões técnicas até o modo de se relacionarem com os pacientes. 0 conhecimento dos pais a respeito da saúde bucal é incipiente, limitado a métodos de higiene bucal e identificação de dor ou fraturas visíveis. E, relativo aos serviços de APS, identificaram-se deficiências na educação em saúde, na organização interna, no tempo de espera pela consulta e na distância entre o domicílio e o local de atendimento.

Com efeito, apesar da garantia do atendimento odontológico, a ausência no comparecimento esteve permeada pelas experiências negativas dos pais. Embora contraditório, mediante tantas 
demandas nos serviços públicos de saúde, as crianças faltosas necessitariam de abordagens diferenciadas, pois apresentaram necessidades que vão além do problema bucal.

Conclui-se que o trabalho intersetorial entre a educação e a saúde possibilitou ampliar o acesso para atendimento dos casos mais graves, a experiência de estágio dos estudantes de Odontologia e a identificação de famílias expostas a riscos e que necessitam de maior proteção social em prol da Promoção da Saúde e da melhoria da qualidade de vida das pessoas.

\section{AGRADECIMENTOS}

O presente trabalho foi realizado com apoio da Coordenação de Aperfeiçoamento de Pessoal de Nível Superior - Brasil (CAPES) - Código de Financiamento 001.

\section{REFERÊNCIAS}

1. Silveira MF, Freire RS, Nepomuceno MO, Martins AMEBL, Marcopito LF. Cárie dentária e fatores associados entre adolescentes no norte do estado de Minas Gerais, Brasil: uma análise hierarquizada. Cien Saude Colet. 2015 Nov;20(11):3351-64. http://dx.doi.org/10.1590/1413812320152011.12262014. PMid:26602713.

2. Casotti E, Contarato PC, Fonseca ABM, Borges PKO, Baldani MH. Atenção em saúde bucal no Brasil: uma análise a partir da avaliação externa do PMAQ-AB. Saúde Debate. 2014 Out;38(spe):140-57. http://dx.doi.org/10.5935/0103-1104.2014S011.

3. Reis WG, Scherer MDA, Carcereri DL. 0 trabalho do cirurgião-dentista na atenção primária à saúde: entre o prescrito e o real. Saúde Debate. 2015 Mar;39(104):56-64. http://dx.doi.org/10.1590/0103110420151040608.

4. Mestriner W Jr, Mestriner SF, Bulgarelli AF, Mishima SM. O desenvolvimento de competências em atenção básica à saúde: a experiência no projeto Huka-Katu. Cien Saude Colet. 2011;16(Supl 1):903-12. http://dx.doi.org/10.1590/S1413-81232011000700022.

5. Brasil. Ministério da Educação. Conselho Nacional de Educação Câmara de Educação Superior. Resolução CNE/CES 3, de 19 de fevereiro de 2002. Institui Diretrizes Curriculares Nacionais do Curso de Graduação em Odontologia. Diario Oficial União [Internet]. Brasília, 4 de março de 2002; Seção 1.p. 10. [citado em 2019 Ago 12]. Disponível em: http://portal.mec.gov.br/cne/arquivos/pdf/CES032002.pdf

6. Brasil. Secretaria Municipal da Saúde. Diretrizes para a atenção em saúde bucal: crescendo e vivendo com saúde bucal. São Paulo: SMS; 2012.

7. Amorim RG, Leal SC, Frencken JE. Survival of atraumatic restorative treatment (ART) sealants and restorations: a meta-analysis. Clin Oral Investig. 2012 Apr;16(2):429-41. http://dx.doi.org/10.1007/s00784-011-0513-3. PMid:21274581.

8. Mickenautsch S, Yengopal V. Failure rate of high-viscosity GIC based ART compared with that of conventional amalgam restorations--evidence from an update of a systematic review. SADJ. 2012 Aug;67(7):329-31. PMid:23951787.

9. Frencken JE. The state-of-the-art of ART restorations. Dent Update. 2014 Apr;41(3):218-20, 222-4. http://dx.doi.org/10.12968/denu.2014.41.3.218. PMid:24839709.

10. Bardin L. Análise de conteúdo. São Paulo: Edições 70; 2011.

11. Kobayashi HM, Pereira AC, Meneghim MC, Ambrosano GMB. Accuracy and reproducibility of dental caries risk classification in São Paulo, Brazil. Arq Odontol. 2012 jul-Set;48:125-33.

12. Correa ACP, Ferreira F, Cruz GSP, Pedrosa ICF. Acesso a serviços de saúde: olhar de usuários de uma unidade de saúde da família. Rev Gaúcha Enferm. 2011;32(3):451-7. http://dx.doi.org/10.1590/S1983-14472011000300003. PMid:22165389. 
13. Peres MA, Iser BPM, Boing AF, Yokota RTC, Malta DC, Peres KG. Desigualdades no acesso e na utilização de serviços odontológicos no Brasil: análise do Sistema de Vigilância de Fatores de Risco e Proteção para Doenças Crônicas por Inquérito Telefônico (VIGITEL 2009). Cad Saude Publica.

2012;28(Supl):S90-100. http://dx.doi.org/10.1590/S0102-311X2012001300010. PMid:22714973.

14. Garcia-Subirats I, Vargas I, Mogollón-Pérez AS, De Paepe P, Silva MRF, Unger JP, et al. Barriers in access to healthcare in countries with different health systems. A cross-sectional study in municipalities of central Colombia and north-eastern Brazil. Soc Sci Med. 2014 Apr;106:204-13. http://dx.doi.org/10.1016/j.socscimed.2014.01.054. PMid:24576647.

15. Assis MMA, Jesus WLA. Acesso aos serviços de saúde: abordagens, conceitos, políticas e modelo de análise. Cien Saude Colet. 2012;17(11):2865-75. http://dx.doi.org/10.1590/S141381232012001100002 . PMid:23175292.

16. Cardoso ACC, Santos RQ Jr, Souza LE, Barbosa MBCB. Inserção da equipe de saúde bucal no PSF um desafio para a melhoria da qualidade de atenção à saúde. Rev Baiana Saúde Pública. 2014 Jan;26(12):94. http://dx.doi.org/10.22278/2318-2660.2002.v26.n1-2.a993.

17. Bordin D, Fadel CB. Pacto pela saúde no Brasil: uma análise descritiva da progressão dos indicadores de saúde bucal. Rev Odontol UNESP. 2012 Out;41(5):305-11. http://dx.doi.org/10.1590/S180725772012000500002.

18. Rodrigues AAAO, Assis MMA. Oferta e demanda na atenção à saúde bucal: o processo de trabalho no Programa Saúde da Família em Alagoinhas-Bahia. Rev Bahiana Saúde Pública. 2014 Jul-Dez;29(2):273-85.

19. Fertonani HP, Pires DEP, Biff D, Scherer MDA. Modelo assistencial em saúde: conceitos e desafios para a atenção básica brasileira. Cien Saude Colet. 2015 Jun;20(6):1869-78. http://dx.doi.org/10.1590/1413-81232015206.13272014. PMid:26060965.

20. Toassi RFC, Davoglio RS, Lemos VMA. Integração ensino-serviço-comunidade: o estágio na atenção básica da graduação em Odontologia. Educ Rev. 2012;28(4):223-42. http://dx.doi.org/10.1590/S0102-46982012000400009.

21. Melo MMDC, Souza WV, Lima MLC, Braga C. Fatores associados à cárie dentária em pré-escolares do Recife, Pernambuco, Brasil. Cad Saude Publica. 2011 Mar;27(3):471-85. http://dx.doi.org/10.1590/S0102-311X2011000300008. PMid:21519698.

22. Carter AE, Carter G, Boschen M, AlShwaimi E, George R. Pathways of fear and anxiety in dentistry: a review. World J Clin Cases. 2014 Nov;2(11):642-53. http://dx.doi.org/10.12998/wjcc.v2.i11.642. PMid:25405187.

23. Olak J, Saag M, Honkala S, Nõmmela R, Runnel R, Honkala E, et al. Children's dental fear in relation to dental health and parental dental fear. Stomatologija. 2013;15(1):26-31. PMid:23732827.

24. Silva AN, Mendonça MH, Vettore MV. The association between low-socioeconomic status mother's Sense of Coherence and their child's utilization of dental care. Community Dent Oral Epidemiol. 2011 Apr;39(2):115-26. http://dx.doi.org/10.1111/j.1600-0528.2010.00576.x. PMid:21029146.

\section{CONFLITOS DE INTERESSE}

Os autores declaram não haver conflitos de interesse.

\section{*AUTOR PARA CORRESPONDÊNCIA}

Glória Lúcia Alves Figueiredo, UNIFRAN - Universidade de Franca, Av. Dr. Armando Salles de Oliveira, 201, 14404-600 Franca - SP, Brasil, e-mail: gloria.figueiredo@unifran.edu.br

Recebido: Agosto 12, 2019

Aprovado: Novembro 21, 2019 